\title{
EFFECTS OF TANK COLOUR ON BODY COLOUR INTENSITY AND GROWTH OF YELLOW GOURAMI TRICHOPODUS TRICHOPTERUS
}

\author{
ASRA NOR IZATY, A. A AND NORAZMI-LOKMAN, N. H. ${ }^{\text {B, }}$ \\ ${ }^{a, b}$ Institute of Tropical Aquaculture and Fisheries Research, Universiti Malaysia Terengganu, 21030 Kuala Nerus, \\ Terengganu, Malaysia \\ * Corresponding author: lokhakim@umt.edu.my
}

\begin{abstract}
Yellow gourami (Trichopodus trichopterus) is a species native to Southeast Asia and is famous as ornamental species. However, hobbyists and farmers encounter problems where its body colour easily becomes faded in captivity. Since colour enhancer pellets are expensive, an experiment was performed to determine whether tank colour can influence the body colour intensity and growth of T. trichopterus. Four different tank colours (white, yellow, blue and green) with five replicates were tested where fish were kept under natural lighting (outdoor) conditions for two months. The results demonstrated that fish reared in green coloured tank showed an increment in its colour intensity while fish reared in white tanks increased its body weight. It can be concluded that tank colour does affect the body colour intensity and weight of $T$. trichopterus. This study will help farmers and hobbyists to solve colour fading problem using a cheaper way.
\end{abstract}

Keywords: Ornamental Fish, Colour Enhancement, Tank

\section{Introduction}

Growing interest in aquarium keeping has attributed to the increased demand in ornamental fishes, especially Trichopodus trichopterus or commonly known as yellow gouramis. Yellow gouramis are one of the popular ornamental species among aquarists. They are famous due to their pretty gold tone and striped pattern along the back with deeper tone colour. Known as omnivorous species, they can literally eat anything and usually do best on a mixed diet of live feeds and pellets such as flake food, micro pellets, brine shrimp, blood worms, and daphnia. These two reasons have made them one of the most wanted ornamental fish and have contributed to the high demand of this species in ornamental industries.

Although ornamental industries keep on developing new technologies in breeding and fish rearing, there is still a lack of appropriate approaches in maintaining body colour of ornamental fish. Most of the aquaculturists nowadays use feed containing carotenoid pigment to enhance the body colour of fish especially ornamental fishes. Carotenoid pigment is an important dietary requirement because of its ability to alter colouration, and it has been well reported in teleost fish as well as many other taxonomic groups (McGraw et al., 2002). However, it is costly and need continuous supplementation to ensure the maintenance of fish body colour.

Colour patterns play an essential part in signalling processes of many fish species (Baron et al., 2008). Fishes use colour basically for signalling during courtship, mating or other intrasexual communication, and for threatening displays, camouflage, and protection from predators by frightening them or alerting that the animal or some part of it is poisonous (Theis et al., 2012). Behavioural correspond with colour patterns proposes that colour pattern signalling may be an important mechanism of communication in fishes with suitable environments such as favourable light and water conditions and also visual systems (Beeching, 1995). Apart from that, previous studies also proved that certain species use colour in choosing their mate such as female guppies Poecilia reticulata unveiled strong preferences for males with relatively high levels of carotenoid colouration based on the expression of orange pigmentation (Evans et al., 2004). 
Fish maintenance in their natural habitats is very different from artificial environments where it may affect the fish physiology and behaviour (Eslamloo et al., 2015). Among teleost, the key to morphological skin colour changes was demonstrated in terms of alterations in skin structure and pigment accumulation during metamorphosis in different species (Leclercq et al., 2010). In vertebrates, the pigmentation of the skin can be altered by hormonal stimulation, and the colour of the background and the illumination are controlling factors for the intensity and the pattern of skin pigmentation (Masazumi, 1993). Background colour is the most superior environmental factor in managing the skin pigmentation in some fish (Van der Salm et al., 2004).

Fish have colour vision and their capability to recognize feed and hence their food intake, growth and survival rate could be influenced by background colour (Papoutsoglou et al., 2000; Strand et al., 2007). Colour perceptions in fishes are due to the rods and retina in their eyes (Joselevitch et al., 2009; Banan et al., 2011). This is stated by (Sabbah et al., 2010) where fish retinas contain rods and cones that react to a specific wavelength range based on their ecological niche. The capacity for colour vision is mediated by the differentiation of the signal intensities from photoreceptors of two or more types that vary in spectral sensitivity (Collin et al., 2004). This is due to changes in environmental colour affecting Melaninconcentrating hormone and Melanocyte stimulating hormone that acknowledge colouring changes on fish (Amiya et al., 2005; Mizusawa et al., 2013).

Melanocyte stimulating hormone $(\mathrm{MCH})$ is a pituitary hormone derived by post-translational processing from pro-opiomelanocortin (POMC) and associated in stress and background customizing (Arends et al., 2000). The effects of a-MSH on behaviour and colour body, combined with morph-specific regulation of the stress response and the melanocortin system, suggest that the melanocortin system promotes the polymorphism in behaviour and coloration in A. burtoni (Dijkstra et al., 2017). However, fish species and life stages react differently to various background colours (Papoutsoglou et al., 2005). The obvious variations in physiological responses which are stressinduced hormones and melatonin and growth are caused by background colour in white and black backgrounds depending on fish species (Amiya et al., 2005).

Background colour effect differs according to species; blue light or ambient colour was demonstrated to enhance fish growth and alter fish physiological responses (Ruchin, 2004); Karakatsouli et al., 2007) but summer flounder (Paralichthys dentatus) and Nile tilapia (Oreochromis niloticus) were not affected by blue light colour (McLean et al., 2008). In previous studies, black and red colour as background highly caused stress while green colour as background was recommended in rearing (Luchiari et al., 2008; Imanpoor et al., 2011).

Different background colours' impacts on fish vision and their behaviour can provide one of the most potential methods that can be used to maintain body colour in yellow gourami Trichopodus trichopterus. It can be another alternative apart from using colour enhancer for their body pigmentation, and this method can ensure the increase in profit for the aquaculturists by omitting the cost of colour enhancer pellets. This study will help hobbyists and aquaculture industry in maintaining body colouration of fish in captive condition.

\section{Materials and Methods}

\section{Fish and rearing protocol}

Twenty male yellow gouramis Trichpodus trichopterus were bought from a local store in a range of $4 \mathrm{~cm}$ to $5 \mathrm{~cm}$ in size and housed in a tank individually. The water of each tank was changed weekly to maintain the water quality. Feeds were given twice daily with artificial feed in the morning at $3 \%$ of their body weight and frozen bloodworm in the evening (Saha et al., 2017) as this fish is omnivores. Low aeration 
was provided continuously and $\mathrm{pHs}$ at the range of 6.0 to 7.5 with temperature of $27-28^{\circ} \mathrm{C}$ were maintained (Baensch and Riehl, 1985). This experiment was conducted in Universiti Malaysia Terengganu's hatchery.

\section{Experimental design}

In this experiment, four different of colours were used which were green (Martinez-Cardenas et al., 2007), blue (Imanpoor et al., 2011), yellow (Strand et al., 2007) and white as control. Each colour consisted of 5 replicates where total of tanks would be used where they would be randomly arranged. This study was conducted for 8 weeks (Booth et al., 2004), where the data of body colour intensity was collected every thirty days (Awasthi et al., 2014) and growth of yellow gourami was taken at the beginning and end of this experiment (Eslamloo et al., 2015).

\section{Body colour intensity}

For the body colour intensity, each sample was anesthetized using Transmore TS-16 with 35 drops for 1.5 Litre of water. DSLR camera was used to take a photo of the fish (NorazmiLokman et al., 2016). Then, images of samples taken were analysed using image $\mathrm{J}$ software analysis for each of image intensity (Collins, 2007).

\section{Growth performance}

For the growth performance of Trichopodus trichopterus, weight and length were measured. The fish was starved overnight, and sample was anesthetized before weight and length measurement was taken. Length of the fish was taken using standard ruler where total length (TL) and standard length (SL) was measured. Several growth parameters for each fish were taken as follows (Mandal et al., 2010):

a) Mean weight gain

$=$ Final body weight-Initial body weight

b) Body weight gain (\% BWG)

$$
=\frac{\text { Final body weight-Initial body weight }}{\text { Initial body weight }}
$$

a) Specific growth rate (SGR)

$\frac{\mathrm{Ln} \text { (Final weight)-Ln (Initial weight }}{\text { Number of days }} \times 100$

\section{Data analysis}

All data taken were subjected to normality test. Analyses were run where one-way analysis of variance (ANOVA) was conducted for growth performance and body colour intensity followed by post hoc test by using software SPSS version 23 (Glover \& Mitchell, 2004; Laerd, 2017).

\section{Results and Discussion}

\section{Body colour intensity}

The results of body colour intensity on Trichopodus trichopterus indicated that there were significant effects of tank colours on body colour intensity. Green coloured tank provided the best performance $(\mathrm{P}<0.05)$ while other colours (white, yellow and blue) showed lesser performance (Figure 4.1).

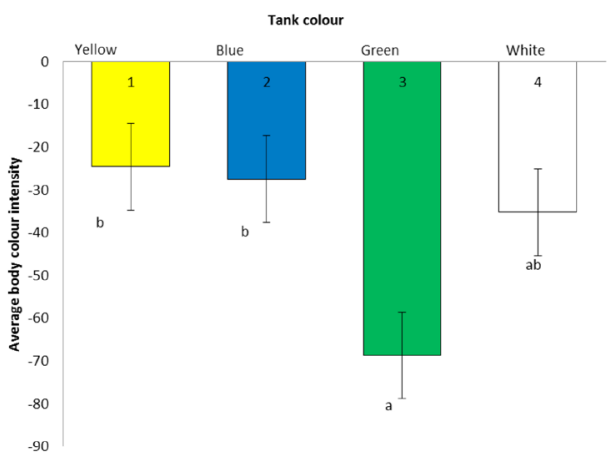

Figure 4.1 The intensity of body colour in yellow gourami, Trichopodus trichopterus reared in different tank colours for two months. Data are presented as mean $\pm S D(n=20)$. Bars with different letters are significantly different $(\mathrm{P}<0.05)$.

Acceptability of consumers is decreased when the skin of fish is paling especially in ornamental fishes (Paripatananont et al., 1999). The intensity of body colour is important to be maintained in order to ensure the continuity of these ornamental fish industries. Many studies have been carried out to investigate the effects of tank colours on the body colour of fish in a 
variety of species. This is due to the different amount of pigment and its dispersion is caused by the changes in tank wall colours (Masazumi, 1993). The results demonstrated that greencoloured tank had the highest changes of initial body colour intensity and final body colour intensity where the skin of Trichopodus trichopterus darkened. Previous studies have proven that some of the skins of fishes darkened when reared in a dark coloured background such as freshwater catfish, Lophhiosilurus alexandri (Costa et al., 2017) and false clownfish, Amphiprion ocellaris (Yasir et al., 2009).

Apart from that, other coloured (white, blue, yellow) tanks affected the T.trichopterus by paling the colour of the skin. Doolan et al., 2008, in his studies of Australian snapper, Pagrus auratus, said that culture environment has a strong effect on skin lightness. Changes in morphology of pigmented cells and its density of skin colour in fish are resulted by the long-term adaptation of background colour (Sugimoto, 2002). This was also supported by Bagnara et al., 1973, where fishes become pale in a light background and dark in a dark background in response to fish adapting to the background, including various shades of the background.

According to Guthrie in 1986, vision acts as a source of sensory information for fish where a diversity of different resources of visible objects can be identified (i.e. texture, colour, brightness, etc.) by the fish due to its complex interactions with the environment and physical nature of light; besides, colour contrast or brightness contrast can also be distinguished. In this study, it was demonstrated that fish vision played an important role in changing of body colour in fish as suggested by (Saszik et al., 2001) where the visual system in fish can be developed by environmental factors depending on species.

Physiological colour skin changes have two different types of mechanisms which are "Primary Colour Response" and "Secondary Colour Response". Primary colour response is a chromatophores personal response to light such as melanophores (black/brown), xanthophores (yellow) and cyanophores (blue) as stated by (Oshima, 2001), while secondary colour response starts off in eyes and run by endocrine or neural system (Roubos et al., 2010). According to Archana et al., 2017, colour changes affected by background colour in most of teleostean fishes have proven that both neural mechanisms and hormonal are combined and also the physiological changes are the combined effect of neurotransmitter working synergistically with hormones. Previous studies stated that brisk alter of skin colour may have been synchronized by the neuro-endocrine system (Van der Salm et al., 2004); Doolan et al., 2007; 2008).

Alpha-melanocyte-stimulating hormone (a-MSH) is the hormone in charge of pigment dispersion (chromatophores) and highly involved in colour changes of fish skin. (Bertolesi et al., 2015) in his studies stated that melanopsin in eyes activates skin pigmentation through a secondary response entailing negative regulation of a-MSH secretion by the pituitary. Apart from involving in action of a-MSH in the skin, it also attaches to other MCRs including those exhibited in the brain, where it adjusts social behaviour, stress physiology and appetite (Cone, 2006; Ducrest et al., 2008). These hormones also have been stated to be involved in increasing the yellowness of cichlid fish by the distributions of xanthophore pigments (Dijkstra et al., 2017).

Thus, the effects of body colour intensity in fishes are controlled by complex interaction of both nervous mechanism and hormonal where they vary among species. In Fundulus heteroclitus (Kleinholz et al., 1938) nervous systems shows to be dominant where the mechanism can evolve according to background for adaptation in the animal and the nerve is exclusively controlled by the melanophores. Dark tanks that caused the darkening of skin can be due to the melanophore dispersion that expands its area of pigmentation and density while paling of skin is due to the low dispersion and aggregations of the melanophores (Sugimoto, 2002; Amiya et al., 2005). Skin darkening could be in response to a-MSH being launched and lead to melanin granules dispersion (Papoutsoglou et al., 2000). (Van 
der Salm et al., 2005) supported this statement in his studies where it has been established that high density of melanophores promoted the skin darkening of O.mossambicus reared in a black background.

\section{Growth performance}

There are seven mortality of Trichopodus trichopterus observed during this experiment. There was significant difference in fish weights between treatments during 2 months after the starting of trial (Figure 4. 1). Specific growth rate (SGR) was significantly increased in fish reared in white tank colours compared to other colour tanks $(\mathrm{P}<0.05)$. The obtained results on growth indicate that white tank colour had the best growth performance in comparison with other tank colours.

Table 4.1: Growth performance of yellow gourami, Trichopodus trichopterus reared in different tank colours for two months.

\begin{tabular}{lcccc}
\hline & \multicolumn{4}{c}{ Tank colour } \\
\hline Parameters & White & Blue & Yellow & Green \\
\hline IBW (g) & 6.27 & 8.0 & 8.8 & 8.01 \\
FBW (g) & 8.06 & 7.31 & 7.29 & 6.79 \\
SGR (\% day $\left.{ }^{-1}\right)$ & 0.44 & -0.16 & -0.33 & -0.29 \\
\hline
\end{tabular}

Note: IBW, Initial Body Weight; FBW, Final Body Weight; SGR, Specific Growth Rate.

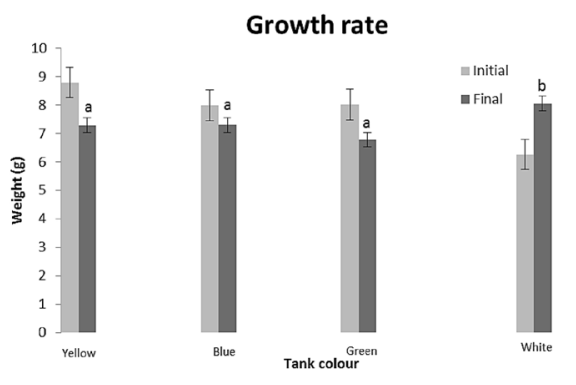

Figure 4.2: The growth performance of yellow gourami, Trichopodus trichopterus reared in different tank colours during two months. Data are presented as mean \pm SD $(n=20)$. Bars with different letters are significantly different $(\mathrm{P}<0.05)$.
The growth performance of Trichopodus trichopterus notably improved in white tank colour in contrast with blue, yellow and green coloured tanks. Previous studies reported that white tanks give favourable results on growth rates for a variety of species such as Onchorhynus mykiss, Cyprinus carpio L (S. Papoutsoglou et al., 2000; Papoutsoglou et al., 2005), Perca fluviatilis L (Strand et al., 2007) and Carassius auratus (Eslamloo et al., 2015). The increased in growth rate of T.trichopterus in this study could be because of the tank colour that was in contrast to the feed given, thereby increasing the probability to be seen by the fish (Jentoft et al., 2006; Strand et al., 2007). The ability of fish to see and eat feed eventually will affect the feed intake and at the same time will impact the growth rate of the fish.

In this study, it can be seen that greencoloured tank had the lowest growth performance due to the highest reduction of final body weight of T.trichopterus. Most studies reported that dark coloured background (i.e. green, black, grey, etc.) either gave a negative feedback or no response towards fish growth performance depending on the fish species. Examples of fish species that have been studied are Salmo salar (Stefansson et al., 1989) and Diplodus puntazzo (Karakatsouli et al., 2015). However, these colour background preferences are different according to species (Imanpoor et al., 2011) because certain species reacted positively towards dark background such as young starlet Acipenser ruthenus (Bayrami et al., 2017) and thinlip mullet Liza ramada larvae (El-Sayed et al., 2011). The growth performance could be affected by the stress response when reared in different tank colour than their natural habitat.

Generally, decrease in growth of various species is caused by chronic stress where it is incorporated with respiration, osmoregulation, tissues repair and movement that lead to body homeostasis to re-establish its energy consumption (Biswas et al., 2006). Stress response due to rearing fish in appropriate colour also has been reported in (McLean et al., 2008). As suggested by (Bayrami et al., 2017), 
fish growth also involves complex biochemical process that associates several neuro systems and hormonal interaction in its body regulation. Fish stress response can be measured by the cortisol levels in blood; however, in this experiment the cortisol level was not measured. In (McLean et al., 2008) study, cortisol level was the highest when reared in blue coloured tank compared to black, green and red. This proved the mortality of three fishes in blue tank was due to the stress which affected the behaviour where it caused the fish to jump out of the tank.

\section{Conclusion}

This study revealed that yellow gourami Trichopodus trichopterus body colour intensity was significantly upgraded when reared in green tank compared to blue, white and yellow coloured tanks. However, growth performance in green tank was in a slower rate compared to T.trichopterus in white tank that had the highest positive growth performance. Thus, when growth rate of T.trichopterus is not the main concern, they can be reared in green coloured tank in order to avoid the loss of their yellow colour. While white tank colour caused the body colour intensity to increase where skin became paling, further studies on how to revert the colour should be considered. Nonetheless, further studies can also investigate the effects of tank colour on T.trichopterus stress response in captivity and their complex behaviour that would help aquaculturists and farmers in the future.

\section{Acknowledgements}

I thank my colleagues from the School of Fisheries and Aquaculture who provided insight and supported me spiritually throughout the research. I wish to express my sincere thanks to my research supervisor, Dr Lokman Nor Hakim Norazmi, for his assistance and dedicated involvement throughout this whole research and my fellow labmates who kindly contributed to the study.

\section{References}

Amiya, N., Amano, M., Takahashi, A., Yamanome, T., Kawauchi, H., \& Yamamori, K. (2005). Effects of tank color on melaninconcentrating hormone levels in the brain, pituitary gland, and plasma of the barfin flounder as revealed by a newly developed time-resolved fluoroimmunoassay. General and Comparative Endocrinology, 143(3), 251-256.

Archana, S., \& Jain, A. (2017). Background adaptation in the Trichogaster trichopterus, blue gourami. International Journal of Fisheries and Aquatic Studies 2017; 5(2): 112-117.

Arends, R., Rotllant, J., Mancera, J., Bonga, S. W., \& Flik, G. (2000). alpha-MSH acetylation in the pituitary gland of the sea bream (Sparus aurata L.) in response to different backgrounds, confinement and air exposure. Journal of endocrinology, 166(2), 427-435.

Awasthi, M., Kashyap, A., \& Serajuddin, M. (2014). Effect of plant meal as a carotenoid source on the development of pigmentation in Dwarf Gourami, Colisa lalia (Hamilton, 1822). Proceedings of the National Academy of Sciences, India Section B: Biological Sciences, 84(4), 1031-1034.

Baensch, H.A. and R. Riehl. (1985). Aquarien atlas. Band 2. Mergus, Verlag für Natur-und Heimtierkunde $\mathrm{GmbH}$, Melle, Germany. $1216 \mathrm{p}$.

Bagnara, J., \& Hadley, M. E. (1973). Chromatophores and colour change. The Comparative Physiology of Animal Pigmentation.

Banan, A., Kalbassi, M., Bahmani, M., \& Sadati, M. Y. (2011). Effects of colored light and tank color on growth indices and some physiological parameters of juvenile beluga (Huso huso). Journal of Applied Ichthyology, 27(2), 565-570. 
Baron, M., Davies, S., Alexander, L., Snellgrove, D., \& Sloman, K. A. (2008). The effect of dietary pigments on the coloration and behaviour of flame-red dwarf gourami, Colisa lalia. Animal Behaviour, 75(3), 1041-1051. doi: https://doi.org/10.1016/j. anbehav.2007.08.014

Bayrami, A., Allaf Noverian, H., \& Asadi Sharif, E. (2017). Effects of background colour on growth indices and stress of young sterlet (Acipenser ruthenus) in a closed circulated system. Aquaculture Research, 48(5), 20042011.

Beeching, S. (1995). Colour pattern and inhibition of aggression in the cichlid fish Astronotus ocellatus. Journal of fish biology, 47(1), 50-58.

Biswas, A. K., Seoka, M., Takii, K., Maita, M., \& Kumai, H. (2006). Stress response of red sea bream Pagrus major to acute handling and chronic photoperiod manipulation. Aquaculture, 252(2-4), 566-572.

Booth, M. A., Warner-Smith, R. J., Allan, G. L., \& Glencross, B. D. (2004). Effects of dietary astaxanthin source and light manipulation on the skin colour of Australian snapper Pagrus auratus (Bloch \& Schneider, 1801). Aquaculture Research, 35(5), 458-464.

Collin, S. P., \& Trezise, A. E. O. (2004). The origins of colour vision in vertebrates. Clinical and Experimental Optometry, 87(4-5), 217-223. doi: 10.1111/j.14440938.2004.tb05051.x

Collins, T. J. (2007). Introduction to Image J for light microscopy. Microscopy and microanalysis, 13(S02), 1674.

Cone, R. D. (2006). Studies on the physiological functions of the melanocortin system. Endocrine reviews, 27(7), 736-749.

Costa, D., Mattioli, C., Silva, W., Takata, R., Leme, F., Oliveira, A., \& Luz, R. (2017). The effect of environmental colour on the growth, metabolism, physiology and skin pigmentation of the carnivorous freshwater catfish Lophiosilurus alexandri. Journal of fish biology, 90(3), 922-935.
Dijkstra, P. D., Maguire, S. M., Harris, R. M., Rodriguez, A. A., DeAngelis, R. S., Flores, S. A., \& Hofmann, H. A. (2017). The melanocortin system regulates body pigmentation and social behaviour in a colour polymorphic cichlid fish. Paper presented at the Proc. R. Soc. B.

Doolan, B. J., Booth, M. A., Jones, P. L., \& Allan, G. L. (2007). Effect of cage colour and light environment on the skin colour of Australian snapper Pagrus auratus (Bloch \& Schneider, 1801). Aquaculture Research, 38(13), 1395-1403.

Doolan, B. J., Allan, G. L., Booth, M. A., \& Jones, P. L. (2008). Effect of carotenoids and background colour on the skin pigmentation of Australian snapper Pagrus auratus (Bloch \& Schneider, 1801). Aquaculture Research, 39(13), 1423-1433.

Ducrest, A.-L., Keller, L., \& Roulin, A. (2008). Pleiotropy in the melanocortin system, coloration and behavioural syndromes. Trends in ecology \& evolution, 23(9), 502510.

El-Sayed, A. F. M., \& El-Ghobashy, A. E. (2011). Effects of tank colour and feed colour on growth and feed utilization of thinlip mullet (Liza ramada) larvae. Aquaculture Research, 42(8), 1163-1169.

Eslamloo, K., Akhavan, S. R., Eslamifar, A., \& Henry, M. A. (2015). Effects of background colour on growth performance, skin pigmentation, physiological condition and innate immune responses of goldfish, Carassius auratus. Aquaculture Research, 46(1), 202-215. doi: 10.1111/are.12177

Evans, J., Bisazza, A., \& Pilastro, A. (2004). Female mating preferences for colourful males in a population of guppies subject to high predation. Journal of fish biology, 65(4), 1154-1159.

Glover, T., \& Mitchell, K., (2004). Introduction to Biostatistics. New York,NY: McGrawHill Education - Europe. 
Guthrie, D. (1986). Role of vision in fish behaviour The behaviour of Teleost fishes (pp. 75-113): Springer.

Imanpoor, M. R., \& Abdollahi, M. (2011). Effects of tank color on growth, stress response and skin color of juvenile Caspian kutum Rtilus frisii Kutum. Global Veterinaria, 6(2), 118125.

Jentoft, S., ØXnevad, S., Aastveit, A. H., \& Andersen, Ø. (2006). Effects of Tank Wall Color and Up-welling Water Flow on Growth and Survival of Eurasian Perch Larvae (Perca fluviatilis). Journal of the World Aquaculture Society, 37(3), 313-317.

Joselevitch, C., \& Kamermans, M. (2009). Retinal parallel pathways: seeing with our inner fish. Vision research, 49(9), 943-959.

Karakatsouli, N., Papoutsoglou, S. E., \& Manolessos, G. (2007). Combined effects of rearing density and tank colour on the growth and welfare of juvenile white sea bream Diplodus sargus L. in a recirculating water system. Aquaculture Research, 38(11), 1152-1160.

Karakatsouli, N., Kassianos, N., \& Papoutsoglou, S. E. (2015). Effects of rearing density and tank colour on juvenile sharpsnout seabream (Diplodus puntazzo) growth performance. Aquaculture international, 23(4), 943-953.

Kleinholz, L., \& Knowles, F. (1938). Studies in the pigmentary system of Crustacea: III. Light-intensity and the position of the distal retinal pigment in Leander adspersus. The Biological Bulletin, 75(2), 266-273.

Laerd. (2017). Statistics Laerd. Available at :https://statistics.laerd.com.

Leclercq, E., Taylor, J. F., \& Migaud, H. (2010). Morphological skin colour changes in teleosts. Fish and fisheries, 11(2), 159-193.

Luchiari, A., \& Pirhonen, J. (2008). Effects of ambient colour on colour preference and growth of juvenile rainbow trout Oncorhynchus mykiss (Walbaum). Journal of fish biology, 72(6), 1504-1514.
Mandal, S. C., Sahu, N. P., Kohli, M. P. S., Das, P., Gupta, S. K., \& Munilkumar, S. (2010). Replacement of live feed by formulated feed: effect on the growth and spawning performance of Siamese fighting fish (Betta splendens, Regan, 1910). Aquaculture Research, 41(11), 1707-1716.

Martinez-Cardenas, L., \& Purser, G. J. (2007). Effect of tank colour on Artemia ingestion, growth and survival in cultured early juvenile pot-bellied seahorses (Hippocampus abdominalis). Aquaculture, 264(1), 92-100.

Masazumi, S. (1993). Morphological color changes in the medaka, Oryzias latipes, after prolonged background adaptation-I. Changes in the population and morphology of melanophores. Comparative Biochemistry and Physiology Part A: Physiology, 104(3), 513-518.

McGraw, K., Hill, G., Stradi, R., \& Parker, R. (2002). The effect of dietary carotenoid access on sexual dichromatism and plumage pigment composition in the American goldfinch. Comparative Biochemistry and Physiology Part B: Biochemistry and Molecular Biology, 131(2), 261-269.

McLean, E., Cotter, P., Thain, C., \& King, N. (2008). Tank color impacts performance of cultured fish. Croatian Journal of Fisheries, 66(2), 43-54.

Mizusawa, K., Kobayashi, Y., Yamanome, T., Saito, Y., \& Takahashi, A. (2013). Interrelation between melanocytestimulating hormone and melaninconcentrating hormone in physiological body color change: Roles emerging from barfin flounder Verasper moseri. General and Comparative Endocrinology, 181, 229-234. doi: https://doi.org/10.1016/j. ygcen.2012.09.026

Norazmi-Lokman, N. H., Purser, G., \& Patil, J. G. (2016). Gravid spot predicts developmental progress and reproductive output in a livebearing fish, Gambusia holbrooki. Public Library of Science One, 11(1), e0147711. 
Oshima, N. (2001). Direct reception of light by chromatophores of lower vertebrates. Pigment Cell \& Melanoma Research, 14(5), 312-319.

Papoutsoglou, S., Mylonakis, G., Miliou, H., Karakatsouli, N., \& Chadio, S. (2000). Effects of background color on growth performances and physiological responses of scaled carp (Cyprinus carpio L.) reared in a closed circulated system. Aquacultural Engineering, 22(4), 309-318.

Papoutsoglou, S. E., Karakatsouli, N., \& Chiras, G. (2005). Dietary L-tryptophan and tank colour effects on growth performance of rainbow trout (Oncorhynchus mykiss) juveniles reared in a recirculating water system. Aquacultural Engineering, 32(2), 277-284.

Paripatananont, T., Tangtrongpairoj, J., Sailasuta, A., \& Chansue, N. (1999). Effect of astaxanthin on the pigmentation of goldfish Carassius auratus. Journal of the World Aquaculture Society, 30(4), 454-460.

Roubos, E. W., Van Wijk, D. C., Kozicz, T., Scheenen, W. J., \& Jenks, B. G. (2010). Plasticity of melanotrope cell regulations in Xenopus laevis. European Journal of Neuroscience, 32(12), 2082-2086.

Ruchin, A. (2004). Influence of colored light on growth rate of juveniles of fish. Fish Physiology and Biochemistry, 30(2), 175178.

Sabbah, S., Laria, R. L., Gray, S. M., \& Hawryshyn, C. W. (2010). Functional diversity in the color vision of cichlid fishes. BioMed Central biology, 8(1), 133.

Saha, S., Behera, S., Bhakta, D., Mandal, A., Kumar, S., \& Mondal, A. (2017). Breeding and embryonic development of an indigenous ornamental fish Trichogaster lalius (Hamilton, 1822) in captive condition. Journal of Entomology and Zoology Studies 2017; 5(3): 111-115.
Saszik, S., \& Bilotta, J. (2001). Constant darkrearing effects on visual adaptation of the zebrafish ERG. International Journal of Developmental Neuroscience, 19(7), 611619.

Stefansson, S., \& Hansen, T. (1989). Effects of tank colour on growth and smoltification of Atlantic salmon (Salmo salar L.). Aquaculture, 81(3-4), 379-386.

Strand, A., Alanärä, A., Staffan, F., \& Magnhagen, C. (2007). Effects of tank colour and light intensity on feed intake, growth rate and energy expenditure of juvenile Eurasian perch, Perca fluviatilis L. Aquaculture, 272(1), 312-318.

Sugimoto, M. (2002). Morphological color changes in fish: Regulation of pigment cell density and morphology. Microscopy Research and Technique, 58(6), 496-503. doi: 10.1002/jemt.10168.

Theis, A., Salzburger, W., \& Egger, B. (2012). The function of anal fin egg-spots in the cichlid fish Astatotilapia burtoni. Public Library of Science one, 7(1), e29878

Van der Salm, A., Martinez, M., Flik, G., \& Bonga, S. W. (2004). Effects of husbandry conditions on the skin colour and stress response of red porgy, Pagrus pagrus. Aquaculture, 241(1), 371-386.

Van der Salm, A., Spanings, F., Gresnigt, R., Bonga, S. W., \& Flik, G. (2005). Background adaptation and water acidification affect pigmentation and stress physiology of tilapia, Oreochromis mossambicus. General and Comparative Endocrinology, 144(1), 51-59

Yasir, I., \& Qin, J. G. (2009). Impact of background on color performance of false clownfish, Amphiprion ocellaris, Cuvier. Journal of the World Aquaculture Society, 40(6), 724-734. 
